\title{
The Relation of Intra-Abdominal Adipose Tissue Accumulation and the Development of Vulnerable Carotid Atherosclerotic Plaques in Diabetes Mellitus
}

Snezana R Markovic-Jovanovic ${ }^{1}$, Muamer H Suljic ${ }^{2}$, Aleksandar N Jovanovic ${ }^{1}$, Vanja P Nickovic ${ }^{3}$, Zoran A Savic ${ }^{4}$, Jadranka Mitic ${ }^{1}$ and Rade Grbic $^{1}$

${ }^{1}$ Medical faculty, University of Pristina, K Mitrovica, Serbia

${ }^{2}$ International University Gorazde, Bosnia and Herzegovina

${ }^{3}$ Clinical-Hospital Center, Pristina, Gracanica, Serbia

${ }^{4}$ Clinical-Hospital Center, K Mitrovica, Serbia

"Corresponding author: Snezana R Markovic-Jovanovic, Medical faculty, University of Pristina, K Mitrovica, Serbia, Tel: +381648412856; E-mail: snezana.markovic.jovanovic@gmail.com

Received date: November 16, 2017; Accepted date: November 27, 2017; Published date: November 30, 2017

Copyright: ( 2017 Markovic-Jovanovic SR, et al. This is an open-access article distributed under the terms of the Creative Commons Attribution License, which permits unrestricted use, distribution, and reproduction in any medium, provided the original author and source are credited.

\begin{abstract}
Objective: The aim of study was determining the relation between the quality of metabolic control, anthropometric parameters and ultrasound measurement of fat accumulation and carotid atherosclerotic plaques vulnerability in patients with type 2 diabetes.

Methods: The study included 51 patients with type 2 diabetes mellitus and 50 healthy individuals. The assessment of plaque vulnerability relies on quantitative and qualitative plaque ultrasound analysis. The thickness of intraabdominal adipose tissue was measured as a distance between the frontal wall of abdominal aorta and the dorsal wall of rectus abdominis muscles; the measurements are performed by placing transducer $5 \mathrm{~cm}$ above the umbilicus.

Results: Atherosclerotic plaque was found in all of diabetic patients, comparing to $28.12 \%$ in the control group; among those, $47.06 \%$ with diabetes and $25.6 \%$ of control patients had vulnerable plaque. The vulnerability of atherosclerotic plaque was significantly related to age, duration of diabetes, glycaemia, waist circumference, waist / hip ratio, intra-abdominal adipose tissue thickness, intra-abdominal/subcutaneous fat ratio, dyslipidemia and hypertension.

Conclusions: Carotid atherosclerotic plaques, particularly vulnerable ones, are far more prevalent in diabetic patients. Advanced age, poor glycemic control, obesity and the intra-abdominal fat accumulation contribute to carotid atherosclerotic plaques vulnerability. Despite the significant correlations with metabolic/anthropometric measurements, none of the predisposing factors could be identified as the independent risk factor; obviously, the increased vulnerability of has been the result of the synergistic effects of multiple pathogenic mechanisms. Moreover, ultrasound measurements of intra-abdominal fat did not show a decisive advantage over the classical anthropometric measurements in estimating atherosclerotic and metabolic risk.
\end{abstract}

Keywords: Diabetes; Abdominal Ultrasound; Carotid atherosclerotic plaques; Atherosclerosis; Visceral adipose tissue

\section{Background}

Diabetes mellitus is metabolic disorder which prominent feature is hypoglycemia. It evolves because of a defect in insulin secretion, impaired insulin action or both pathological features.

Type 2 diabetes may be associated with multiple abnormalities leading to vascular disease: obesity, insulin resistance, hyperglycemia, dyslipidemia, hypertension, and renal disease, with the first five of those disorders forming an entity termed "metabolic syndrome". These abnormalities may lead to heart disease by accelerating atherosclerosis and causing endothelial cell dysfunction, oxidative stress, inflammation, and vascular remodeling.
The critical terminal event in atherosclerosis that leads to acute coronary syndromes (such as coronary artery disease, stroke and sudden cardiac death) is a phenomenon called plaque instability. When plaques become unstable and erode or rupture, platelets in the bloodstream are exposed to plaque elements that can trigger acute thrombotic vascular occlusion [1]. Diabetic macrovascular complications - myocardial infarction and stroke - are the leading cause of mortality in diabetic patients. These macrovascular complications are especially common in patients with metabolic syndrome and even more in people with type 2 diabetes [2].

It is believed that patients with diabetes have a much higher incidence of plaque rupture comparing to non-diabetics [3]. Macrophage death, or apoptosis, may cause plaque necrosis, plaque disruption and acute atherothrombotic vascular events [4]. Plaque necrosis and atherothrombotic disease are markedly increased in diabetes [5]. The Tabas laboratory discovered a macrophage apoptosis pathway that appears to be highly relevant to advanced atherosclerosis. 
Citation: Markovic-Jovanovic SR, Suljic MH, Jovanovic AN, Nickovic VP, Savic ZA, et al. (2017) The Relation of Intra-Abdominal Adipose Tissue Accumulation and the Development of Vulnerable Carotid Atherosclerotic Plaques in Diabetes Mellitus. J Diabetes Metab 8: 775. doi: $10.4172 / 2155-6156.1000775$

Page 2 of 6

The major components of the pathway involve combinatorial signaling through 2 major pathway s: a pathway triggered by engagement of a family of cell surface receptors called pattern recognition receptors (PRRs) and a cell stress pathway known as the unfolded protein response (UPR), which involves a critical set of membranes in cells called the endoplasmic reticulum. This mechanism of macrophage death is referred to as the PRR-UPR model. UPR is responsible for the most dangerous types of human coronary artery plaque disruptions [6]. Although diabetic patients may be more susceptible to stroke than non-DM patients, there was no significant difference in carotid plaque ultrasound characteristics and distributions between them; however, it seems that the extent of atherosclerosis-implicated inflammation may be more advanced in patients with DM [7].

Unstable plaques are potentially thrombogenic or emboligenic, and may directly induce ischemic disorders. Hypoechoic, echolucent (lipid) plaques are most unstable and vulnerable [8] they are prone to rupture while the atheromatous content may have an immediate procoagulant activity leading to occlusion of coronary or cerebral arteries. There is a strong correlation between the presence of hypoechogenic plaques and the incidence of the ischemic events assessed by the intracranial CT; a longitudinal, prospective study [9], indicate the correlation between incidence of hypoechogenic plaques and the subsequent of ischemic cerebral infraction in individuals who were asymptomatic at the time of examination. Therefore, the presence of hypoechoic plaques delineates a significant risk for stroke. Unregulated diabetes and hypercholesterolemia increase the incidence of hypoechogenic plaques lesion.

\section{Objective}

The aim of study was determining the relation between the quality of metabolic control, anthropometric parameters and ultrasound measurement of fat accumulation and carotid atherosclerotic plaques vulnerability in patients with type 2 diabetes.

\section{Methods}

Evaluation of the atherosclerotic plaque vulnerability was performed on the Toshiba Cori Vision Pro and Madison device; it was based on translucency of plaque, its global appearance, plaque structure homogeneity, dimensions, edge regularity, plaque surface quality and clarity of fibrous cap.

Along with the assessment of the plaque vulnerability, we have performed the following important carotid arteries ultrasonographic evaluations:

- Assessment of intima;

- Quantitative assessment of plaques (length, width, thickness, artery diameter);

- The presence of thrombus, quantitative and qualitative assessment of the thrombus and appositional thrombus growth.

- The degree of stenosis caused by plaque and / or thrombus;

- The presence of an aneurysm or abnormalities in course and geometry (tortuosity, kinking, and coiling) of the carotid arteries;

- Determining of the volume flow;

- The presence of arrhythmias and Doppler frequency waves.

On ultrasound scanning, plaque appears as a localized thickening of the intima (spreading from the internal elastic lamina to the luminal side of intima), which protrudes toward the lumen. The localization of the plaque (at proximal, middle or distal segment of the artery), its length, a cross-section position on the wall (front, rear, medial, lateral) and plaque shape (pearlescent, oval, circumferential, irregular) may be determined at the doppler ultrasound longitudinal cross section of the carotid artery. According to its length (after the recommendations of Neurology Laboratory at Wake Forest University School of Medicine (8), the plaques may be classified as small (1-2 mm), middle-sized (2-4 $\mathrm{mm}$ ) or large ( $>4 \mathrm{~mm})$.

The assessment of a plaque ultrasound density is performed by comparing the plaque density with the hypoechogenic displays of carotid artery intraluminal blood and of surrounding soft tissues (qualitative scoring system). According to this system a plaque may be classified as following five types: type 1 (hypoechoic, or echolucent plaque which contains homogenous distribution of echoes, except for an anechogenic rim which represents the fibrous cap); type 2 (hypoechoic, or echolucent plaque that contains heteroechogenic distribution of echoes-50\% or more of plaque contains hypoechoic elements); such ultrasonographical display corresponds to a lipidfibrous plaque; type 3 (hypoechoic or echdense plaque that contains heteroechogenic distribution of echoes, with $50 \%$ or more of plaque contains hyperechoic elements-fibro-lipid plaque); type 4 (hypoechoic or echdense plaque that has homogenous distribution of hyperechoic elements-fibrous plaque); type 5 (calcified plaque, containing the acoustic shadow, sometimes big enough to preclude the evaluation of plaque).

\section{Atherosclerotic plaques may also be clinically classified as}

- Complicated (vulnerable, unstable)

- Uncomplicated (non- vulnerable, stable).

The thickness of intraabdominal adipose tissue was measured as a distance between the frontal wall of abdominal aorta and the dorsal wall of rectus abdominis muscles; the measurements are performed by placing transducer $5 \mathrm{~cm}$ above the umbilicus. Using the $3.5 \mathrm{MHz}$ transducer, at the end of expirium during the quiet breathing (Figure 1).

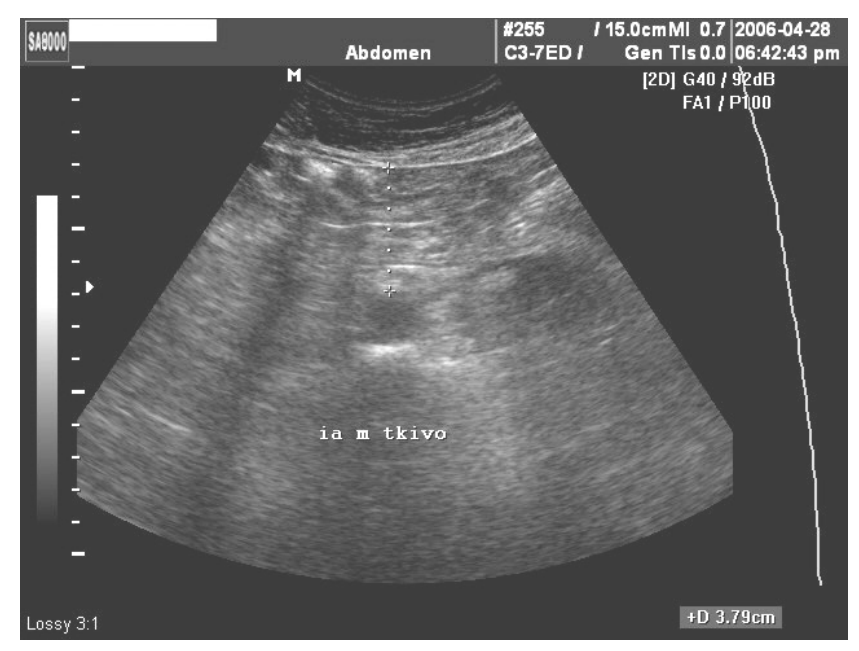

Figure 1: Determination of intraabdominal fat thickness.

Subcutaneous fat tissue thickness is determined by the $3.5 \mathrm{MHz}$ ultrasonic transducer, at the same position, by measuring the distance between the skin and frontal edge of $m$. rectus abdominis. 
Citation: Markovic-Jovanovic SR, Suljic MH, Jovanovic AN, Nickovic VP, Savic ZA, et al. (2017) The Relation of Intra-Abdominal Adipose Tissue Accumulation and the Development of Vulnerable Carotid Atherosclerotic Plaques in Diabetes Mellitus. J Diabetes Metab 8: 775. doi: $10.4172 / 2155-6156.1000775$

Page 3 of 6

Weight and height are determined by standard anthopometric methods. BMI values were calculated as the weight $/$ height ${ }^{2}$ ratio. Waist-to-hip ratio was calculated by dividing the waist circumference measured at the widest part of the waist and the hip circumference measured at the level of iliac crest.

Plasma cholesterol was determined by colorenzymatic method (PAP) and plasma triglycerides by colorenzymatic ESPA-S method. The arterial blood pressure measurements are obtained according to standard clinical procedures. Statistical comparisons between the groups regarding mean age, mean ultrasound adipose tissue measurements, anthropometric parameters, mean average glucose, plasma lipids and arterial blood pressure were performed by Student's T-test (small independent samples). Fort the comparison of nonnumerically expressed and ordinal parameters with uncertain distances between the categories (such as parameters expressing the plaque vulnerability) we used non-parametric Mann-WhitneyWilcoxon test; multiple correlation analysis and multiple regression analysis were used to evaluate relation between the different parameters in the whole sample of assessed individuals.

This study has been conformed to Helsinki Declaration and was approved by Medical Faculty Ethics Committee, University of Pristina/K Mitrovica. All adult participants provided written consent to participate in this study.

\section{Results}

The study included 101 patients (both genders) 51 of whom had confirmed type 2 diabetes mellitus, for a period longer than five years. The control group consisted of 50 healthy individuals, with no morbidities. The average age was $62.42 \pm 10.14$ and $57.63 \pm 12.12$ years, $(p>0.05)$ in diabetics and control group, respectively; therefore, the age difference between the groups did not influence the results significantly.

Figures 2 and 3 shows the mean thickness of subcutaneous (Figure 2) and intra-abdominal adipose tissue in type 2 diabetics and in the control group. The difference in the amount of subcutaneous fat was insignificant; on the other hand, an apparent and highly significant difference $(\mathrm{p}<0.01)$ in the mean intraabdominal fat thickness between the diabetics and healthy individuals was identified (35.11 \pm 15.58 vs. $26.12 \pm 14.14 \mathrm{~cm}$, respectively).

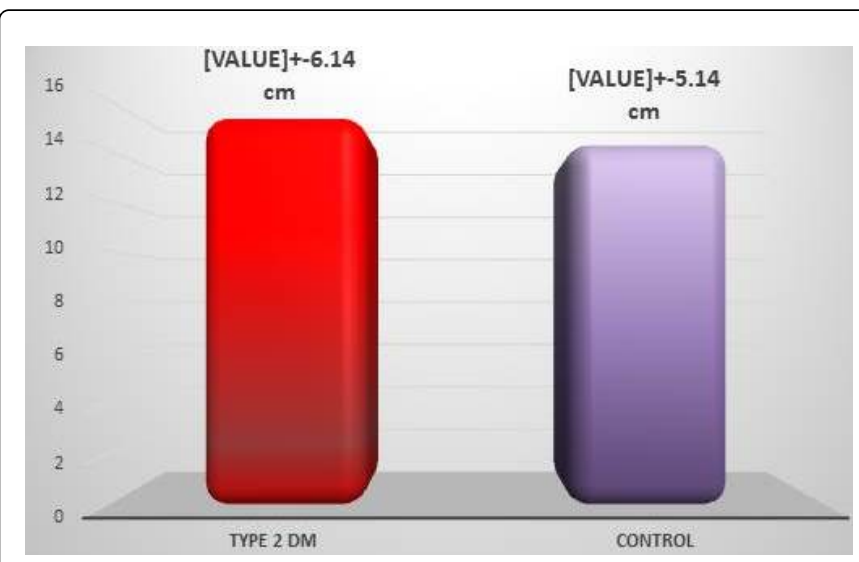

Figure 2: Mean thickness of subcutaneous fat in the group with type 2 diabetes mellitus and control group.

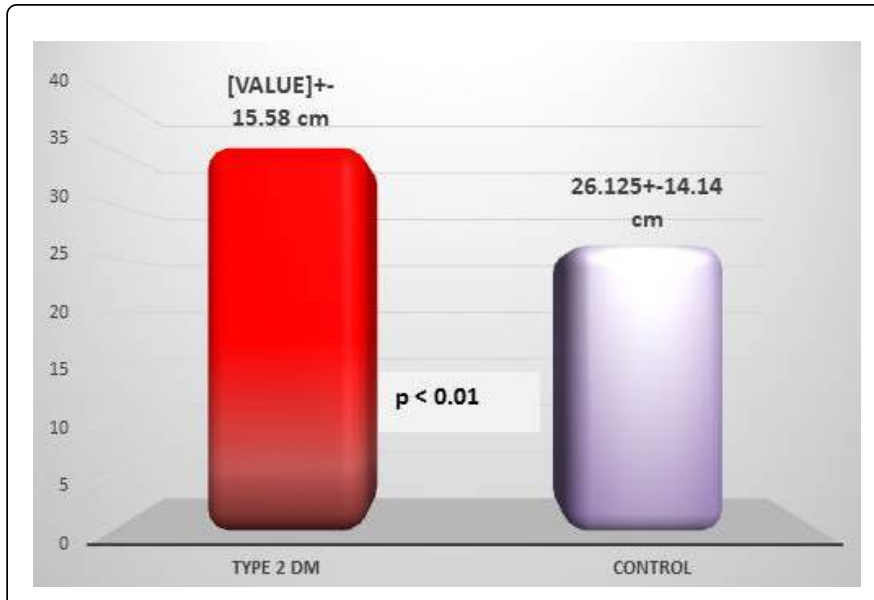

Figure 3: The mean value of intraabdominal fat in the group with type 2 diabetes mellitus and control group.

Figure 4 shows the distribution of patients according to the presence and type of atherosclerotic plaque in the carotid arteries in the study and control group. Atherosclerotic plaque was found in all diabetic patients, comparing to $28.12 \%$ in the control group; among those, $47.06 \%$ with diabetes and $25.6 \%$ of control patients had vulnerable plaque. The difference in the plaque distribution among the two groups of patients was highly significant.

According to the results of our study, the thickness of visceral fat is related to the presence of diabetes, the degree of atherosclerotic plaque vulnerability, waist size, waist/hip ratio, the thickness of the subcutaneous fat tissue, intra-abdominal/subcutaneous adipose tissue ratio, body mass, the incidence of hypertension and hyperlipoproteinemia (Table 1).

\begin{tabular}{|c|c|c|}
\hline \multicolumn{3}{|c|}{ INTRAABDOMINAL FAT THICKNESS } \\
\hline & $\begin{array}{l}\text { Spearman's } \\
\text { Correlation } \\
\text { coefficient }(\rho)\end{array}$ & $\begin{array}{l}\text { Statistical } \\
\text { significance }(p)\end{array}$ \\
\hline Type 2 diabetes morbidity & 0.293 & $p=0.004$ \\
\hline $\begin{array}{l}\text { Atherosclerotic plaque } \\
\text { vulnerability }\end{array}$ & 0.267 & $p=0.007$ \\
\hline Waist circumference & 0.733 & $p<0.0001$ \\
\hline Waist/hip ratio & 0.43 & $p<0.0001$ \\
\hline Subcutaneous fat thickness & 0.453 & $p<0.0001$ \\
\hline $\begin{array}{l}\text { Intraabdominal/subcutaneous } \\
\text { fat thickness }\end{array}$ & 0.598 & $p<0.0001$ \\
\hline Body weight & 0.593 & $p<0.0001$ \\
\hline Hyperlipoproteinemias & 0.226 & $p=0.021$ \\
\hline Arterial hypertension & 0.389 & $\mathrm{p}<0.0001$ \\
\hline
\end{tabular}

Table 1: Statistically significant correlations between the intaabdominal fat thickness and the assessed clinical, athropometric and ultrasonographic parameters. 
Citation: Markovic-Jovanovic SR, Suljic MH, Jovanovic AN, Nickovic VP, Savic ZA, et al. (2017) The Relation of Intra-Abdominal Adipose Tissue Accumulation and the Development of Vulnerable Carotid Atherosclerotic Plaques in Diabetes Mellitus. J Diabetes Metab 8: 775. doi: $10.4172 / 2155-6156.1000775$

Page 4 of 6

The of the intraabdominal/subcutaneous adipose tissue thickness ratio was significantly associated with the incidence and duration of diabetes, patients' age, plaque vulnerability, waist circumference, intra- abdominal/subcutaneous adipose tissue, body weight and the presence of hypertension (Table 2).

\section{Patients with type 2 diabetes melitus}
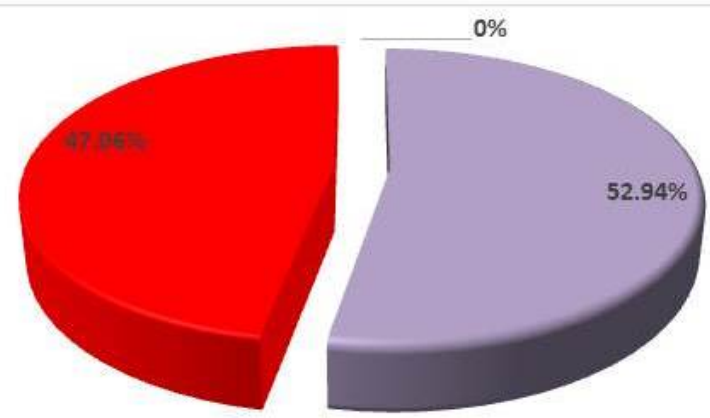

Wo changes 1 Non-vulnerable plaque

\section{Control group}

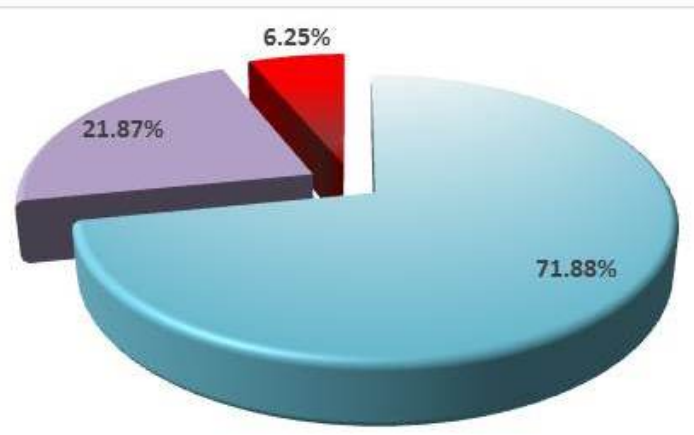

MNo changes Mon-vulnerable plaque

Figure 4: Distribution of atherosclerotic plaque types in patients with type 2 diabetes melitus and in control group.

\begin{tabular}{|l|l|l|}
\hline \multicolumn{3}{|l|}{ INTRAABDOMINAL / SUBCUTANEOUS FAT RATIO } \\
\hline & $\begin{array}{l}\text { Spearman's correlation } \\
\text { coefficient ( } \rho)\end{array}$ & $\begin{array}{l}\text { Statistical } \\
\text { significance (p) }\end{array}$ \\
\hline Type 2 diabetes morbidity & 0.359 & $p<0.0001$ \\
\hline Age & -0.383 & $p=0.001$ \\
\hline $\begin{array}{l}\text { Atherosclerotic } \\
\text { vulnerability }\end{array}$ & 0.262 & $p=0.008$ \\
\hline The duration of diabetes & 0.293 & $p=0.007$ \\
\hline Waist circumference & 0.262 & $p=0.009$ \\
\hline Intraabdominal fat thickness & 0.598 & $p<0.0001$ \\
\hline Subcutaneous fat thickness & -0.327 & $p=0.001$ \\
\hline Body weight & 0.159 & $p=0.075$ \\
\hline Arterial hypertension & 0.388 & $p<0.0001$ \\
\hline
\end{tabular}

Table 2: Statistically significant correlations between the intaabdominal / subcutaneous fat thickness ratio and the assessed clinical, athropometric and ultrasonographic parameters.

The vulnerability of atherosclerotic plaque (Table 3) correlated with incidence and duration of diabetes, age, glycemic control, body weight, waist circumference, waist/hip ratio, the intraabdominal adipose tissue thickness, intra-abdominal/subcutaneous adipose tissue thickness ratio, dyslipidemia and hypertension.

\begin{tabular}{|l|l|l|}
\hline \multicolumn{2}{|l|}{ ATHEROSCLEROTIC PLAQUE VULNERABILITY } \\
\hline & $\begin{array}{l}\text { Spearman's } \\
\text { correlation coefficient } \\
(\boldsymbol{\rho})\end{array}$ & $\begin{array}{l}\text { Statistical } \\
\text { significance (p) }\end{array}$ \\
\hline Diabetes morbidity & 0.709 & $\mathrm{p}<0.0001$ \\
\hline
\end{tabular}

\begin{tabular}{|l|l|l|}
\hline Age & 0.738 & $\mathrm{p}<0.0001$ \\
\hline The duration of diabetes & 0.659 & $\mathrm{p}<0.0001$ \\
\hline Glycaemia & 0.692 & $\mathrm{p}<0.0001$ \\
\hline Waist circumference & 0.334 & $\mathrm{p}=0.001$ \\
\hline Waist/hip ratio & 0.54 & $\mathrm{p}<0.0001$ \\
\hline Intraabdominal fat thickness & 0.267 & $\mathrm{P}<0.01$ \\
\hline $\begin{array}{l}\text { Intraabdominal/subcutaneous } \\
\text { fat thickness }\end{array}$ & 0.262 & $\mathrm{P}<0.01$ \\
\hline Body weight & 0.579 & $\mathrm{p}<0.0001$ \\
\hline Hyperlipoproteinemia & 0.164 & $\mathrm{P}<0.01$ \\
\hline Arterial hypertension & 0.477 & $\mathrm{p}<0.0001$ \\
\hline & &
\end{tabular}

Table 3: Statistically significant correlations between the atherosclerotic plaque vulnerability and the assessed clinical, athropometric and ultrasonographic parameters.

Despite clear and statistically significant correlations, linear regression analysis did not prove that any of the parameters implied could be considered a sole predictor of vulnerability of atherosclerotic plaque (Table 4). Regarding to the lack of statistical significance, the multiple logistic regression was not indicated.

\begin{tabular}{|l|l|l|}
\hline \multicolumn{2}{|l|}{ ATHEROSCLEROTIC PLAQUE VULNERABILITY } \\
\hline & $\begin{array}{l}\text { Regression } \\
\text { coefficient }\left(\mathbf{r}^{2}\right)\end{array}$ & $\begin{array}{l}\text { Statistical } \\
\text { significance }(p)\end{array}$ \\
\hline Diabetes morbidity & 0.548 & 0.42 \\
\hline Diabetes duration & 0.374 & 0.24 \\
\hline Blood glucose & 0.357 & 0.12 \\
\hline
\end{tabular}


Citation: Markovic-Jovanovic SR, Suljic MH, Jovanovic AN, Nickovic VP, Savic ZA, et al. (2017) The Relation of Intra-Abdominal Adipose Tissue Accumulation and the Development of Vulnerable Carotid Atherosclerotic Plaques in Diabetes Mellitus. J Diabetes Metab 8: 775. doi: $10.4172 / 2155-6156.1000775$

Page 5 of 6

\begin{tabular}{|l|l|l|}
\hline Age & 0.208 & 0.13 \\
\hline Waist circumference & 0.32 & 0.2 \\
\hline Waist/hip ratio & 0.416 & 0.28 \\
\hline Intraabdominal fat thickness & 0.269 & 0.09 \\
\hline Subcutaneous fat thickness & 0.04 & 0.27 \\
\hline $\begin{array}{l}\text { Intraabdominal/subcutaneous } \\
\text { thickness ratio }\end{array}$ & 0.172 & 0.62 \\
\hline Body weight & 0.379 & 0.44 \\
\hline Hyperlipoproteinemias & 0.161 & 0.57 \\
\hline Arterial hypertension & 0.377 & 0.053 \\
\hline
\end{tabular}

Table 4: Results of the linear regression analysis between the atherosclerotic plaque vulnerability and the relevant clinical, anthropometric, biochemical and ultrasonographic parameters.

\section{Discussion}

After a long period of asymptomatic disease atherosclerotic plaques may suddenly rupture, causing a life-threatening thrombosis. Plaque rupture exposes the highly thrombogenic necrotic material to the bloodstream. The main predisposing factor for plaque rupture is thin plaque fibrous cap. However, thrombi can also form without apparent rupture, by plaque erosion. The mechanisms involved in plaque erosion remain largely unknown, although coronary spasm may be responsible. The calcified nodule has been suggested as a rare cause of coronary thrombosis in highly calcified and tortious arteries in older individuals [10].

While inducing the deterioration of other cardiovascular risk factors, obesity by itself independently carries a major cardiovascular risk. The 10 years follow up in Cardiovascular Health Study (1991) revealed a clear correlation between the presence of cardiovascular risk factors and IM thickening in the distal part of the CCA (common carotid artery) and the proximal part of the ICA (internal carotid artery) [11]. Diabetic patients in our study had a higher amount of both subcutaneous and intra-abdominal (visceral) adipose tissue comparing to controls. While the difference in the mean subcutaneous tissue thickness was unremarkable, the diabetic patients had significantly higher mean intraabdominal tissue thickness.

Subcutaneous or peripheral adipose tissue has lower lipolytic activity compared with central (visceral, intraabdominal) fat; therefore, it may serve as safe metabolic storage for circulating free fatty acids, preventing their accumulation in the central compartment. Accumulation of intraabdominal (visceral) adipose tissue, and increased ratio of visceral to subcutaneous fat may increase both metabolic and cardiovascular risk [12]; the insulin resistance plays an essential role in pathophysiology of both conditions and insulin resistance is often related to "central" or "visceral" obesity. Intraabdominal adipocytes secrete retinol-binding protein 4 which may increase insulin resistance. A large amount of free fatty acids are released from the visceral adipocytes and a systemic inflammation vascular and coagulation disorders that accompany diabetes may predispose to cardiovascular incidents [13]. Our results also show that the intraabdominal adipose tissue thickness was inherently related to the diabetes morbidity and the increased incidence of arterial hypertension.

Adipose tissue secretes several proteins-leptin, angiotensinogen, adipsin, acylation-stimulating protein, adiponectin, retinol-binding protein, tumor necrosis factor alpha, interleukin 6, plasminogen activator inhibitor-1, fasting-induced adipose factor, metallothionein, fibrinogen-angiopoietin-related protein, metallothionein and resistin. Resistin itself may be responsible for inducing insulin resistance [14].

Our results revealed the moderate correlation between the quantity of visceral fat and the occurrence of hyperlipidemia and arterial hypertension; again, the ratio of intraabdominal/subcutaneous adipose tissue significantly correlated with the occurrence of hypertension.

Dyslipidemia often accompanies diabetes. The central problem is increase in the hepatic production of VLDL which leads to an increase in triglyceride levels. This leads to increase in LDL cholesterol via VLDL-IDL-LDL pathway. Triglycerides also suppress fibrinolysis, stimulate PAI-1 production in endothelial cells and increase factor VII activity. In addition, LDL cholesterol reduces the amount of nitric oxide in various ways, thus increasing production of superoxide ions [15].

Carotid contrast enhanced ultrasound imaging (CEUS) revealed that a substantial proportion of the carotid plaques in patients with diabetes may be of vulnerable plaques; in a minority of the patients with diabetes, the plaque surface was disrupted. According to the recent study, intraplaque neurovascularisation (IPN) may be predicting future cardiovascular events in patients who recently suffered a cardiovascular event [16]; IPN may contribute to destabilization of the atherosclerotic plaques, leading to an increased risk of rupture. Yet, Maria et al [7] in a study involving 300 patients of which hundred-thirteen had DM (37.7\%) found that patients with DM had similar carotid intima-media thickness to non-diabetics in both vessel- and patient-based analysis $(0.85 \pm 0.18$ versus $0.86 \pm 0.21 \mathrm{~mm}$, $\mathrm{p}=0.83 ; 0.95 \pm 0.17$ versus $0.94 \pm 0.17 \mathrm{~mm}, \mathrm{p}=0.62$, respectively). Patients with DM only exhibited higher $\Delta \mathrm{T}$ (thermal heterogeneity) in both vessel- and patient-based analysis $\left(0.85 \pm 0.50^{\circ} \mathrm{C}\right.$ versus $0.74 \pm$ $0.46^{\circ} \mathrm{C}, \mathrm{p}=0.007 ; 1.03 \pm 0.51$ versus $0.91 \pm 0.46^{\circ} \mathrm{C}, \mathrm{p}=0.03$, respectively). In our study, however, the incidence of atherosclerotic plaques was more than three times higher in patients with type 2 diabetes; when comparing only patients with evident atherosclerotic changes, type 2 diabetics still had two times higher incidence of vulnerable plaques.

Staub et al. [17] performed standard and contrast-enhanced carotid ultrasound in 147 patients (mean age 64+11 years); most of the patients had an increased cardiovascular risk profile and $31 \%$ had diabetes. Atherosclerotic plaques were detected in $76 \%$ of the patients (maximum plaque thickness of $2.8+0.8 \mathrm{~mm}$ ). IPN was noted in 60 patients (54\%).

Vulnerability of atherosclerotic plaques in our study significantly correlated with the amount of intraabdominal adipose tissue $(\mathrm{p}=0.007)$ and the intraabdominal / subcutaneous adipose tissue ratio $(\mathrm{p}=0.008)$. However, based on the result of multiple regression analysis, none of these factors can be defined as independent or as a major risk factor for the development of vulnerable atherosclerotic plaque. Obviously, the vulnerability of atherosclerotic plaque resulted from the synergistic effects of multiple pathogenic factors. Moreover, although the ultrasound measurements of visceral fat may be more exact than anthropometric measurements, neither intra-abdominal fat thickness nor intra-abdominal/subcutaneous fat thickness ratio showed better correlation with atherosclerotic and metabolic changes comparing to waist/hip ratio and waist circumference. 
Citation: Markovic-Jovanovic SR, Suljic MH, Jovanovic AN, Nickovic VP, Savic ZA, et al. (2017) The Relation of Intra-Abdominal Adipose Tissue Accumulation and the Development of Vulnerable Carotid Atherosclerotic Plaques in Diabetes Mellitus. J Diabetes Metab 8: 775. doi: $10.4172 / 2155-6156.1000775$

Page 6 of 6

It is believed [16-18] that in the predisposition to vulnerable plaque formation involve reduced synthesis of collagen, increased collagenase activity and arterial smooth muscle myocyte apoptosis. These changes are especially evident in the plaque parts mostly exposed to the action of mechanical forces. During the plaque cap rupture, procoagulant and tissue factors are released into bloodstream, predisposing for thrombus formation, and subsequently, a predisposition for acute ischemic incident. However, although the rupture of plaques occurs continuously throughout the organism, only some of them may cause the occlusion of the blood vessels and have clinical significance.

\section{Conclusion}

Carotid atherosclerosis is highly prevalent in diabetic patients. Advanced age, diabetes, glycemic control, obesity (as defined by body mass index and/or anthropometric measurements) as well as the abdominal fat distribution increases the carotid plaques vulnerability and risk of ischemic incidents in diabetic patients. Intraabdominal fat thickness and intraabdominal/subcutaneous fat ratio determined by ultrasonography significantly correlated with the vulnerability of carotid atherosclerotic plaques. However, based on the result of multiple regression analysis, none of these factors can be defined as independent or as a major risk factor for the development of vulnerable atherosclerotic plaque. Obviously, the vulnerability of atherosclerotic plaque resulted from the synergistic effects of multiple pathogenic factors. Moreover, ultrasound measurements of intraabdominal fat did not show a decisive advantage over the classical anthropometric measurements in estimating atherosclerotic and metabolic risk.

\section{References}

1. Aikawa M, Libby P (2004) The vulnerable atherosclerotic plaque: pathogenesis and therapeutic approach. Cardiovasc Pathol 13: 125-138.

2. Ambrose JA, Tannenbaum MA, Alexopoulos D, Hjemdahl-Monsen CE, Leavy J, et al. (1998) Angiographic progression of coronary artery disease and the development of myocardial infarction. J Am Coll Cardiol 12: 56-62.

3. Libby P (2001) Current concepts of the pathogenesis of the acute coronary syndromes. Circulation 104: 365-372.

4. Tabas I (2005) Consequences and therapeutic implications of macrophage apoptosis in atherosclerosis: the importance of lesion stage and phagocytic efficiency. Arterioscler Thromb Vasc Biol 25: 2255-2264.

5. Virmani R, Burke AP, Kolodgie F (2006) Morphological characteristics of coronary atherosclerosis in diabetes mellitus. Can J Cardiol 22: 81B-84B.
6. Myoishi M, Hao H, Minamino T, Watanabe K, Nishihira K, et al. (2007) Increased endoplasmic reticulum stress in atherosclerotic plaques associated with acute coronary syndrome. Circulation 116: 1226-1233.

7. Drakopoulou MI, Toutouzas K, Benetos G, Bounas P, Synetos A, et al. (2014) Patients with Diabetes Mellitus and coronary artery disease exhibit higher carotid artherosclerotic plaque inflammation: insights from a new noninvasive method. J Am Coll Cardiol 63: A1082.

8. Bradley WG, Daroff RB, Fenichel GM, Jankovic J (2004) Neurology in Clinical Practice: Principles of diagnosis and management In: Bradley WG (Eds) Neurological investigations and related clinical neurosciences. Elsevier, Philadelphia Pp: 645-650.

9. Gupta A, Kesavabhotla K, Baradaran H, Kamel H, Pandya A, et al. (2015) Plaque Echolucency and Stroke Risk in Asymptomatic Carotid Stenosis. A Systematic Review and Meta-Analysis. Stroke 46: 91-97.

10. Bentzon JF, Otsuka F, Virmani R, Falk E (2014) Acute Coronary Syndromes Compendium, Mechanisms of Plaque Formation and Rupture. Circulation Research 114: 1852-1866.

11. Fried LP, Borhani NO, Enright P, Furberg CD, Gardin JM, et al. (1991) The Cardiovascular Health Study: design and rationale. Ann Epidemiol 1: 263-276.

12. Donnelly LF, O'Brien KJ, Dardzinski BJ, Poe SA, Bean JA, et al. (2003) Using a Phantom to Compare MR Techniques for Determining the Ratio of Intraabdominal to Subcutaneous Adipose Tissue. AJR Am J Roentgenol 2003; 180: 993-998.

13. Jovanovic A, Stolic RV, Rasic DV, Markovic-Jovanovic S, Peric VM (2014) Stroke and Diabetis ketoacidosis-some diagnostics and therapeutics considerations. Vasc Health Risc Manag 10: 201-204.

14. Kelley DE (2002) Skeletal muscle triglycerides: an aspect of regional adiposity and insulin resistance. Ann N Y Acad Sci $967: 135-145$.

15. Trayhurn P, Beattie JH (2001) Physiological role of adipose tissue: white adipose tissue as an endocrine and secretory organ. Proc Nutr Soc 60: 329-339.

16. Lefer AM (2000) Nitric Oxide: A Critical Determinant in IschemiaReperfusion. In: Ignarro LJ(1stedn) Nitric Oxide Biology and Pathobiology. Academic Press, Los Angeles CA, Pp 649-660

17. Staub D, Patel MB, Tibrewala A, Ludden D, Johnson M, et al. (2010) Vasavasorum and plaque neovascularization on contrast-enhanced carotid ultrasound imaging correlates with cardiovascular disease and past cardiovascular events. Stroke 41: 41-47.

18. van den Oord SC, Akkus Z, Renaud G, Bosch JG, van der Steen AF, et al. (2014) Assessment of carotid atherosclerosis, intraplaque neovascularization, and plaque ulceration using quantitative contrastenhanced ultrasound in asymptomatic patients with diabetes mellitus. Eur Heart J Cardiovas Imaging 15: 1213-1218. 